\title{
Materiales didácticos visuales: Formación y trabajo docente en el área de Lengua y Literatura
}

\author{
Visual Didactic Resources: Teacher training in Language and Literature
}

\author{
LUCAS GAGLIARDI, \\ ISFDyT № 9, Universidad Nacional de La Plata, Buenos Aires, Argentina
}

luke in spanish@yahoo.com.ar

\section{Resumen}

Presentamos en este artículo los resultados de una encuesta realizada en Argentina en torno a una temática específica de la Didáctica de la Lengua y la Literatura: los materiales didácticos visuales. En la aproximación de este trabajo indagamos en información cuantitativa y cualitativa por medio de una encuesta que releva ambos tipos de datos. Nuestro objetivo fue revisar a) los saberes de los docentes en acerca de la cultura visual y los vínculos de esta con la disciplina que enseñan; b) la presencia de formación docente de grado o posterior en relación con la temática del estudio. La indagación nos reveló que existe una distancia notable entre formación y práctica profesional; también mostró que los docentes asignan un gran valor a la dimensión visual de los materiales didácticos en los procesos de enseñanza-aprendizaje y que ponen en juego criterios para su uso. Los resultados del estudio nos muestran la necesidad de fortalecer un aspecto de las trayectorias formativas docentes, aspecto que se encuentra en estrecho contacto con su trabajo cotidiano.

Palabras clave: Materiales didácticos, imagen, paratexto, formación docente, lengua, literatura

\section{Abstract}

This article presents the results of an inquiry carried forward in Argentina and related to Didactic of Language and Literature: visual didactic resources. In this study we examine both qualitative and quantitative data by means of an enquiry which takes into consideration both kinds of date. Our aim is to a) revise the teacher's knowledge on visual culture in relation to their area of expertise; b) the presence or absence of specific teacher training around visual teaching materials. The study revealed a noteworthy distance between training and actual professional practice; it also showed that teachers assign an important value to the visual dimension of teaching materials and that despite having little to no preparation at all, they implement criteria to make use of such resources. The results of this study show the necessity of a bolder teacher training regarding this aspect of their every-day professional activities.

Key words: Didactic resources, image, paratext, teacher training, language, literature

\section{DOI https://doi.org/10.36799/el.v6i2.114}

Recibido 11 de febrero de 2021

Aceptado 30 de junio de 2021

Publicado 1 de julio de 2021

Cómo citar este artículo: Gagliardi, L. «Materiales didácticos Visuales: Formación y trabajo docente en el área de lengua y literatura». Estudios 入ambda. Teoría y práctica de la didáctica en lengua y literatura., 6.2, (2021): 1-25, https://doi.org/10.36799/el.v6i2.114

Derechos de autor: La(s) persona(s) autora(s) conservan en todo momento sus derechos morales y patrimoniales sobre la obra; la obra no se puede alterar, transformar o ampliar; siempre debe reconocerse la autoría del documento referido. Ninguna de las modalidades de los documentos publicados en "Estudios $\lambda$ ambda. Teoría y práctica de la didáctica en lengua y literatura" tienen fines comerciales de naturaleza alguna. 


\section{Introducción}

Los materiales didácticos constituyen una dimensión cotidiana para el trabajo docente. En gran medida, la bibliografía destinada a conceptualizar y clasificar los materiales de enseñanza proviene del campo de la Tecnología Educativa, un conjunto de estudios que se inscribe dentro de disciplinas como la Didáctica General de las Ciencias de la Educación o en los estudios en Comunicación y Educación. Tanto es así, que los trabajos sobre materiales de enseñanza producidos desde las didácticas específicas retoman, en la mayoría de los casos, las categorías elaboradas por las disciplinas mencionadas.

Investigaciones recientes (Gagliardi, 2020a, 2020b; López Corral, 2015, 2020) en el campo de la Didáctica de la Lengua y la Literatura (DLL) registran y explican algo que los docentes y formadores advierten en sus prácticas: que en las aulas se recurre a una gama de recursos marcada por la multimodalidad (Kress y Van Lewen, 2006). Sin embargo, las reflexiones específicas sobre la producción de materiales didácticos para la enseñanza de la lengua y la literatura no abundan; muchos menos son, entre aquellos estudios, los que piensan la especificidad de los elementos visuales en la enseñanza del área curricular. Son aún menos los estudios que trabajan con la especificidad de los elementos visuales en la enseñanza del área curricular. En esto parecería repetirse algo que se encuentra en la genética del pensamiento escolar argentino. Dussel $(2009,2012)$ constata el uso de elementos visuales en las aulas desde la génesis de la escuela argentina (por medio de láminas, gabinetes, mapas, libros, afiches, etc.) y en los escritos de pedagogos como Víctor Mercante. Aun así, esos materiales siempre han estado bajo sospecha o han sido mirados como recursos subsidiarios con respecto a la palabra escrita, a tal punto que, según la especialista, no abunda hoy en día el uso crítico de los mismos.

Con el fin de indagar las prácticas docentes, sus conocimientos y trayectorias formativas, encaramos este trabajo de sondeo. Como primer acercamiento al tema, este artículo busca identificar algunas recurrencias en la formación y trabajo docente. A partir de la exploración realizada encontramos una notable distancia entre la formación transitada por los encuestados y las prácticas que desarrollan en su ámbito profesional.

Realizamos una última aclaración terminológica antes de continuar con nuestro desarrollo. Utilizamos la denominación curricular "Lengua y Literatura" ya que es la que se encuentra en los Núcleos de Aprendizaje Prioritarios (Ministerio de Educación, 2006), es decir, los documentos curriculares cuya cobertura es nacional en todos los niveles del sistema educativo. Algunas de las jurisdicciones (como la provincia de Buenos Aires) poseen otras denominaciones para el espacio curricular (por ejemplo, "Prácticas 
del Lenguaje"); estas responden a las orientaciones específicas para la currícula de dicho territorio. Si bien el estudio fue pensado para docentes de educación secundaria, como se verá, participaron también docentes de educación primaria donde el área curricular de Lengua y Literatura también existe.

\section{Marco teórico}

\subsection{Didáctica y formación docente}

La perspectiva que adoptamos para concebir la mirada hacia la actividad educativa es la que nos proporciona la didáctica específica, también llamada especial o de objeto (Cuesta y Bombini, 2006; Cuesta, 2019; Davini, 2008). Esta denominación identifica a conjuntos de saberes sobre la práctica educativa que son producidos en y desde el análisis de la enseñanza de contenidos disciplinares. En particular, nos situamos en la DLL, entendida como disciplina de intervención y análisis acerca de los procesos de enseñanzaaprendizaje de los saberes curriculares sobre lengua y literatura y acerca de la propia formación docente (Cuesta, 2012, 2019).

Utilizamos también para ello aportes que provienen de otros campos de la reflexión educativa. Por un lado, mencionaremos algunas ideas tomadas de la antropóloga Elsie Rockwell (2009). Esta investigadora afirma que las indagaciones etnográficas en el campo educativo registran lo "no documentado", ese conjunto de saberes, prácticas y materialidades que los sujetos involucrados en el territorio observado (docentes, alumnos) conocen pero que suelen escapar a la mirada de las teorías y al registro sistemático de las instituciones. Por otro lado, tomamos el estudio de Antonio Viñao (2002), quien reflexiona sobre el trabajo docente en sus dimensiones históricas, políticas e institucionales. Tanto con Rockwell como con Viñao podemos advertir que la práctica profesoral deja ver estrategias y creaciones que van más allá de la formación de base, así como advertir recurrencias y dificultades del quehacer docente.

La constatación de la presencia de materiales visuales y multimodales en la escuela nos motiva a indagar en la formación docente, en la práctica y política educativa. Dora Riestra y Stella Maris Tapia (2014) explican que la tarea docente se encuentra atravesada por tres dimensiones: el trabajo prescripto por las políticas educativas (localizado en diseños curriculares, planes de estudio, leyes, etc.); el trabajo representado (lo que los docentes creen que deben o no hacer, las representaciones acerca de su tarea que pueden recuperarse por medio de instrumentos como la encuesta o la entrevista); y por último, el trabajo real (es decir, el que efectivamente se desarrollan y que puede trabajarse por medio del análisis de propuestas, observación de clases, seguimiento de los trabajos y devoluciones, etc.). En este artículo nos 
valemos fundamentalmente del concepto de trabajo representado para analizar la segunda sección de la encuesta. En menor medida aludiremos al trabajo prescripto y real para comentar algunos otros puntos en nuestro estudio.

\subsection{Materiales didácticos y visualidad}

Soslayando la complejidad que entraña la definición del concepto de material didáctico (Área Moreira, 2004; Imperatore 2009), diremos que entendemos por tal "a aquellos con los que el estudiante interactúa en forma directa como parte de su proceso de construcción de conocimientos" (Schwartzman, 2013). Para los efectos de la investigación no profundizamos en la taxonomía que separa materiales didácticos (concebidos para la educación) y educativos (concebidos para otros fines y apropiados por el docente y alumnos) (Imperatore, 2009; Schwartzman, 2013). Sí los diferenciamos de los medios de enseñanza, entendiendo por esto último el hardware o soportes materiales que no poseen capacidad semiótica, sino que mediatizan los signos y mensajes (proyectores, computadoras, pizarrón, etc.).

En cuanto a la denominación material didáctico visual (MDV), que empleamos en la encuesta, daremos algunas precisiones. Uno de los objetivos del estudio es indagar en los conocimientos de los encuestados sobre el tema. Por ese motivo no utilizamos denominaciones más precisas debido a que estas podían volverse un obstáculo denominativo para los informantes. El adjetivo "visual", en sentido estricto, puede abarcar tanto materiales con imágenes visuales (signos icónicos, simbólicos o indiciales) como elementos textuales escritos. Como nos recuerda Maite Alvarado (1995), el texto se presenta en la página mediatizado por una tipografía o caligrafía que constituye, en sí, un signo visual. Como se observará en varias de las respuestas, algunos docentes dan importancia a este aspecto para identificar materiales visuales también. Podemos decir, semióticamente hablando, que los materiales visuales suelen identificarse prototípicamente con signos icónicos (es decir, los que guardan relación de semejanza con el referente, como una fotografía de un paisaje con el lugar en cuestión).

Tomamos también una noción clave para pensar la visualidad de los materiales que utilizamos en clase. El concepto de cultura visual designa un objeto que rebasa los límites de la producción artística para abarcar los signos visuales en su conjunto (Capasso, 2020; Hernández, 2010; Mitzoreff, 1999) y a una perspectiva que puede dar cuenta de estos. Esto supone pensar no solo en las imágenes canónicas del arte sino en otras manifestaciones que nos rodean cotidianamente, eliminando las distinciones entre "alta" y "baja" cultura e incorporando campos como el diseño gráfico o los estudios multimediales. En segundo, la categoría de 
cultura visual puede dialogar con disciplinas como el lenguaje visual (Acaso, 2006; Capasso, 2020; Ciafardo, 2010), la semiótica, el análisis del discurso u otras afines que despliegan una mirada sobre los componentes y sus significados, pero sin reducirse a un formalismo vacío de sentidos. Por último, al correr la mirada de lo artístico dejamos uno de los principales obstáculos que sesgan la mirada sobre la visualidad: la concepción de "creatividad" y de "placer estético".

\section{Metodología}

Dada la finalidad de este estudio, el diseño metodológico de esta investigación fue cuantitativocualitativo. El motivo de esta elección abreva en los modos en que hemos concebido la didáctica, la formación y el trabajo docente. A los efectos de investigar las prácticas desde dicho marco, se vuelve necesario recabar datos tanto de las recurrencias y sus proporciones como información acerca de las representaciones que los informantes ponen en juego. Como instrumento de investigación que reúne aspectos cuantitativos y cualitativos utilizamos una encuesta anónima con 25 puntos (véase el Anexo). Las consignas de resolución cerrada (es decir, aquellas que tienen respuestas predefinidas para escoger) apuntan a obtener información cuantitativa mientras que las de resolución abierta permiten que los informantes justifiquen y complementen sus elecciones en otros puntos de la encuesta. Esta doble aproximación permite de un relevamiento integral del trabajo docente representado y real.

La formulación de las preguntas se basó en intereses y problemáticas detectadas en instancias de formación docentes en las que hemos participado como docente o integrante de equipos docentes. En el marco del curso de extensión "Diseño de materiales didácticos para lengua y literatura" de 2019 ${ }^{1}$ pudimos detectar una serie de inquietudes e intereses en torno a la temática a partir de las intervenciones de los asistentes. Dicha experiencia nos permitió elaborar una primera serie de preguntas que fuimos ajustando al momento de diseñar el instrumento de investigación.

El formulario fue diseñado con la herramienta Formularios Google. Las consignas se agruparon en tres secciones o componentes: Información profesional (datos generales relacionados con los estudios de base y desempeño de los encuestados); materiales (consignas referidas al reconocimiento y uso de materiales didácticos visuales por parte de los encuestados); formación en la temática (sección abocada a la

\footnotetext{
${ }^{1}$ El curso fue dictado junto con la Prof. Manuela López Corral en la Facultad de Humanidades y Ciencias de la Educación (Universidad Nacional de La Plata). Contó con la asistencia de docentes del nivel secundario, tanto de Lengua y Literatura como de Lenguas Extranjeras.
} 
identificación de espacios formativos relacionados con el tema de investigación). Para la puesta a disposición del formulario se construyó una red de distribución que incluyó: dos grupos de docentes en la red social Facebook; difusión por medio de lista de correo a instituciones de formación (universitarias y terciarias); solicitud a los participantes para que reenviasen la encuesta a otros posibles interesados. La encuesta se administró durante un período de 60 días entre febrero y abril de 2020.

Para el análisis de los datos obtenidos y su codificación se realizó una primera aproximación a través de la observación los datos estadísticos que ofrece Formularios Google. No obstante, y dada la posibilidad de errores e incongruencias, se realizó una indagación más profunda, tanto para verificar la validez de los datos cuantitativos como para detectar aspectos cualitativos relevantes y filtrar posibles respuestas no válidas (aquellas donde se observaron omisiones de respuestas obligatorias o datos mal consignados).

Se volcaron los datos de las respuestas en una plantilla de cálculo y se procedió a la observación de correlaciones entre las respuestas de las diferentes secciones. A partir de las mismas se hicieron algunas inferencias iniciales. Se revisaron los porcentajes y se filtraron las respuestas no válidas. Siguiendo los lineamientos de la teoría fundamentada (Strauss y Corbin, 2002), luego del primer contacto con los datos observados, se realizó un cotejo con bibliografía específica sobre el tema. Esta aproximación no se realizó con anterioridad para evitar sesgos de confirmación. Utilizamos también una consulta a fuentes auxiliares normativas (diseños curriculares, planes de estudio, sitios web institucionales) para indagar en algunos datos y encontrar posibles explicaciones a lo observado.

\section{Resultados}

\subsection{Totales}

Exponemos los resultados generales de la encuesta. Como se observa en la Tabla 1, el porcentaje de respuestas invalidadas fue mínimo.

Tabla 1.

Resultados generales.

\begin{tabular}{lcc}
\hline & Cantidad & Porcentaje \\
\hline Respuestas totales & 87 & $100 \%$ \\
Válidas & 84 & $96,6 \%$ \\
No válidas & 3 & $3,4 \%$ \\
\hline
\end{tabular}

Fuente: Elaboración propia. 


\subsection{Perfiles profesionales}

En el formulario consignamos una pregunta $\left(\mathrm{N}^{\mathrm{o}}\right.$ 1) referida al lugar de residencia solo a título informativo. Este dato mostró una preponderancia de respuestas de Ciudad Autónoma de Buenos Aires (CABA) y Provincia de Buenos Aires (Tabla 2), por lo cual interpretaremos los datos como una representación parcial en términos territoriales y jurisdiccionales. La observación de las correlaciones con otros datos de la encuesta manifiesta que el distrito de residencia no resulta un factor clave frente a otros como la institución donde se cursó la formación de grado.

Tabla 2.

Procedencia de los encuestados.

\begin{tabular}{lcc}
\hline Jurisdicción & Cantidad & Porcentaje \\
\hline Buenos Aires & 54 & $64,28 \%$ \\
CABA & 17 & $20,23 \%$ \\
Otras provincias & 13 & $15,49 \%$ \\
\hline
\end{tabular}

Fuente: Elaboración propia.

La formación de base de los encuestados (Tabla 3) muestra una preponderancia de profesores en Letras/Lengua y Literatura, un número reducido de docentes de primaria y, sorpresivamente, la presencia de profesionales formados en una carrera no docente: la Licenciatura en Letras.

Tabla 3.

Formación de base.

\begin{tabular}{lcc}
\hline Carrera & Cantidad & Porcentaje \\
\hline Profesorado en Letras/Lengua y Literatura & 74 & $88,09 \%$ \\
Licenciatura en Letras & 4 & $4,76 \%$ \\
Profesorado en Educación Primaria & 8 & $7,14 \%$ \\
\hline
\end{tabular}

Fuente: Elaboración propia.

Cabe destacar que el $95 \%$ de los encuestados se desempeña en la actualidad como docente. De todos los participantes, solo el 11,4 \% aún no ha completado sus estudios de grado en la carrera consignada y se trata en todos los casos de estudiantes de Profesorado en Letras/Lengua y Literatura. Se observó también una paridad en el tipo de institución de educación superior en la cual realizaron sus estudios los encuestados. Este dato, no obstante, revela una segmentación que observaremos en relación con la tercera sección de la encuesta.

Tabla 4.

Instituciones de la formación de grado.

\begin{tabular}{lcc}
\hline Institución formativa & Cantidad & Porcentaje \\
\hline Universidad & 44 & $52,38 \%$ \\
ISFD & 40 & $47,62 \%$ \\
\hline
\end{tabular}

Fuente: Elaboración propia. 


\subsection{Saberes en torno a los materiales visuales}

Pasaremos a ver cuáles son los conocimientos que los entrevistados ponen en juego tanto para identificar materiales visuales como para advertir vínculos entre aspectos de estos y su práctica docente. Es decir, en esta sección nos aproximamos, con las salvedades correspondientes, al trabajo real (Riestra y Tapia, 2014). Nuestro análisis de este grupo de respuestas enfatizará el aspecto cualitativo.

Para la pregunta 9 (¿Cuáles de los siguientes ejemplos considera como "materiales visuales"?) seleccionamos 6 ejemplos (Imagen 1) de recursos que pueden vincularse con contenidos de Lengua y Literatura. Los mismos poseen un grado diverso de prototipicidad: oscilan entre lo predominantemente icónico y lo predominantemente simbólico-lingüístico.

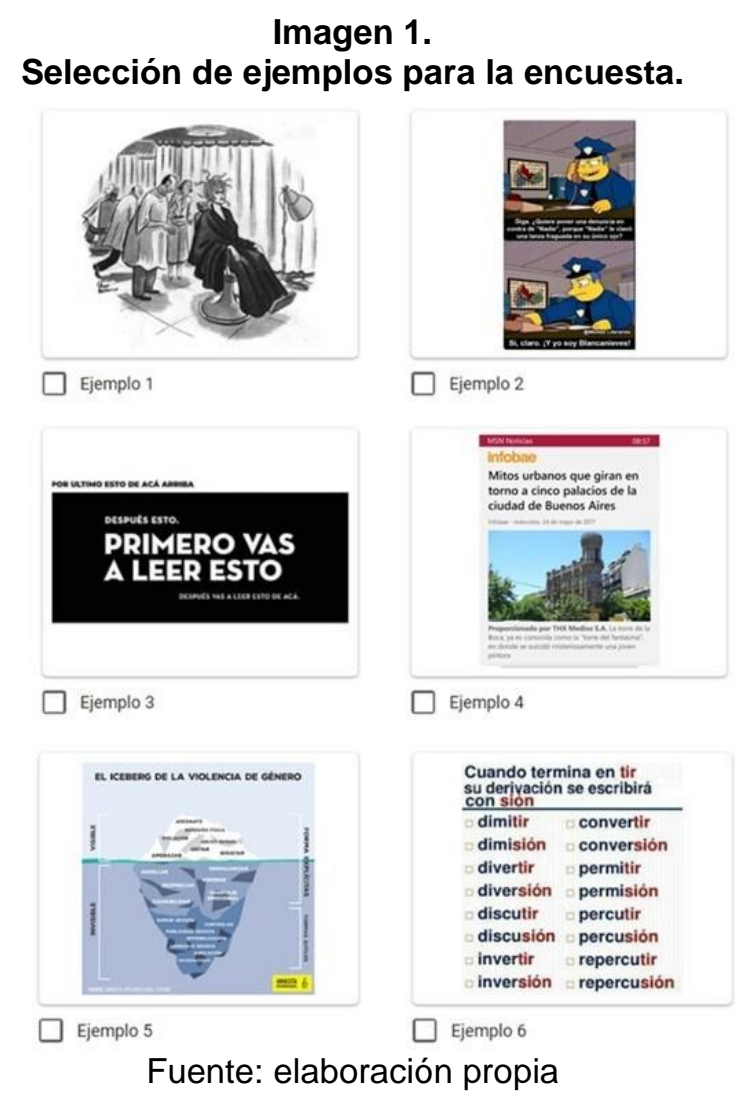

A diferencia de las anteriores preguntas, en este caso los encuestados podían escoger más de una opción en sus respuestas. Por ese motivo, los porcentajes de la Tabla 5 reflejan la proporción en que cada ejemplo fue elegido dentro de las 84 resoluciones de la encuesta.

Tabla 5.

Ejemplos de materiales visuales.

Caso Cantidad Porcentaje

Ejemplo $1 \quad 82 \quad 97,61 \%$

$\begin{array}{lll}\text { Ejemplo } 2 & 74 & 88,09 \%\end{array}$




\begin{tabular}{ccc}
\hline Ejemplo 3 & 72 & $85,71 \%$ \\
Ejemplo 4 & 52 & $61,09 \%$ \\
Ejemplo 5 & 74 & $88,09 \%$ \\
Ejemplo 6 & 42 & $45 \%$ \\
\hline
\end{tabular}

Fuente: Elaboración propia.

Estos resultados confirman la rotunda claridad de la identificación de lo visual con la imagen icónica, como en la ilustración (ejemplo 1), predominantemente icónica como en el meme (ejemplo 2) o en una relación de equilibrio como en la infografía (ejemplo 5) donde el vínculo linguiístico-icónico es indisociable. Hay una clara diferencia entre estos tres ejemplos y aquellos donde predomina la representación del código lingüístico (ejemplos 4 y 6).

La elección del ejemplo 3 en una proporción del 86\% parece una incongruencia a simple vista, ya que fue elegida por informantes que excluyeron los ejemplos 4 y el 6 (siendo este último el más similar al 3). Sin embargo, creemos que existe una posible explicación: el ejemplo 3 es una composición tipográfica que tematiza la importancia de la jerarquía visual de los paratextos y cómo esta incide sobre la lectura. Su forma y contenido coinciden abiertamente, mientras que en el ejemplo 6, el contenido se concentra en un aspecto que no se vincula de inmediato con la configuración formal (la ortografía). Es decir, el ejemplo 3 señaliza la importancia de su dimensión visual. ${ }^{2}$

Las respuestas que siguen dejan entrever cierto grado de diversidad en los criterios de selección. Se confirma aquí la tendencia de identificar lo visual con lo icónico. La consigna 10 pedía a los informantes que explicaran brevemente por qué excluyeron alguno de los ejemplos anteriores. Empecemos por algunas intervenciones de informantes que escogieron la totalidad de los ejemplos como MDV. Aunque en ese caso no era obligatorio responder la consigna 10 , algunos de los encuestados lo hicieron: ${ }^{3}$

Todos son materiales visuales. Incluso 3 y 6 están pensados para connotar desde lo visual, sino serían textos planos.

Iba a excluir el ejemplo numero 6 pero luego me di cuenta de que los colores poseen relevancia en la imagen.

Estas respuestas señalan que se dio relevancia a signos visuales mínimos como el color para resaltar que, en efecto, todos los ejemplos, constituían MDV y que no solo los casos con mayor iconicidad poseían esa dimensión.

\footnotetext{
2 Esta concepción se encuentra también dentro de cierto sector de los estudios de lenguaje visual que desconsideran la paratextualidad tipográfica. Esto puede verse, por ejemplo, en casos como Acaso (2006), cuyo libro se propone como "análisis del lenguaje visual" pero en verdad se concentra en los signos icónicos en detrimento de otros signos también visuales.

${ }^{3}$ Respetamos la redacción y ortografía de las respuestas.
} 
Analicemos ahora las respuestas de quienes omitieron casos como 3, 4 y 6 .

El material visual se reconoce cuando el texto presenta una combinación del uso de códigos entre los cuales el código verbal no se destaca como el dominante.

Porque hay textos en ellas lo cual hace que no sea específicamente visual.

Es una noticia, no hay recursos visuales en juego.

En los materiales visuales la carga informativa está en el uso de imágenes. Si predomina el texto, la imagen es solamente paratexto.

El 6 no tiene elementos visuales. Solo escritura.

Depende, pero podría considerarse 3 como texto periodístico.

Estas respuestas reafirman una identificación de lo visual como sinónimo de iconicidad. En varios de los testimonios se ve el signo lingüístico escrito y la imagen como excluyentes. Se observa claramente con el ejemplo 4: varios testimonios solo advierten la textualidad de la noticia periodística. Si bien se invoca el concepto de paratextualidad, no se llega a considerar que la tipografía es también parte de ese aparato de presentación del mensaje tanto como lo son los otros elementos (Alvarado, 1995). Otras de las respuestas citadas muestran como criterio de elección la distribución de elementos semióticos de acuerdo al grado de predominancia o subordinación.

Estas respuestas parecen marcar cierta falta de sistematicidad en las categorías, pues algunas de las conceptualizaciones se contradicen. En el mejor de los casos, lo que estas respuestas nos muestran es una relativa dificultad de precisión categorial, dificultad que podría vincularse con la formación de base. Sin embargo, el aspecto que resultó esclarecedor, sobre todo a la luz del análisis de la tercera sección de la encuesta, es la constatación de que aquella dificultad categorial o conceptual no se muestra reñida con el trabajo docente y el uso de los MDV para pensar intervenciones didácticas (Tablas 6 y 7). Las siguientes tablas corresponden a las consignas 13 y 15 respectivamente.

Tabla 6.

Selección de materiales.

\begin{tabular}{lcc}
\hline ¿Cuándo usted selecciona materiales educativos tiene en cuenta aspectos visuales? & Cantidad & Porcentaje \\
\hline Sí & 81 & $96,42 \%$ \\
No & 3 & $3,57 \%$ \\
\hline
\end{tabular}

Fuente: Elaboración propia. 
Tabla 7.

Elaboración de materiales.

¿Cuándo usted prepara sus propios materiales didácticos (consignas, cuadernillos, imágenes, etc.) tiene en cuenta aspectos visuales?

Fuente: Elaboración propia.

Los resultados de las Tablas 6 y 7 muestran que la amplia mayoría de los encuestados produce o selecciona materiales teniendo en cuenta la dimensión visual. Por el contrario, cuando solicitan trabajos a los estudiantes (pregunta 17) solo un 18,2\% admite tener en cuenta permanentemente los aspectos visuales en la resolución de los trabajos por parte de los alumnos, un 79, 5\% lo hace solo en ocasiones y 2,3 dice no hacerlo nunca. Lo que se observa aquí es que el énfasis en la visualidad se impone rotundamente en la enseñanza. Sin embargo, en lo que atañe al aprendizaje y la producción de los estudiantes, ese énfasis se diluye o no se considera necesariamente una parte integral del quehacer estudiantil.

En la pregunta 14 indagamos en los aspectos que tienen en cuenta los docentes para incorporar tales materiales a sus propuestas didácticas. Uno de los criterios que prevaleció en la mayoría de las respuestas no tuvo que ver con el contenido de los materiales sino con aspectos compositivos y técnicos como la legibilidad en relación con la tipografía y la resolución de las imágenes. Esto quiere decir que, aunque muchos no hayan conceptualizado en el punto la tipografía como paratexto y signo visual, sí la consideran al momento de plantear un trabajo con los MDV. La preocupación aquí parece ser que el material se muestre apto para ser utilizado por los alumnos en los aspectos que atañen directamente a la navegabilidad del MDV:

La legibilidad y su relación con el diseño de la imagen

Que sea de buena calidad, clara tamaño grande busco varias opciones de esa imagen y elijo la mejor a mi criterio

Todo lo paratextual que puedo manejar (tipografía, interlineado, imágenes no deformadas y de calidad, etc.)

Normalmente se trata de objetos producidos por otros que tomo prestados, y a sea a través de sitios web o redes sociales. Cuando los selecciono, tengo en cuenta que si son a color no pierdan el sentido al pasar al blanco y negro, por ejemplo.

Los colores, los tamaños de las letras, los destacados

el diseño, la jerarquización de la información, y que estéticamente sea agradable para la lectura (tamaños de letra, espacios vacíos, etc.) 
La caligrafía que sea clara y de un tamaño no demasiado chico. Si es un texto literario que tenga un vocabulario que ayude a su comprensión, en un recuadro separado.

Por ejemplo, cuando solo uso textos, me interesa la tipografía y la disposición espacial.

La relación entre diseño y legibilidad.

Paletas cromáticas, organización de la información, nitidez de la imagen, capacidad de síntesis en la misma

En segundo lugar, dentro de los criterios expuestos, aparece la accesibilidad a los materiales para su uso en clase: capacidad de reproducción, duración, costos, tecnología que requieren:

Que efectivamente pueda usarlos en clase, en el marco de las condiciones materiales del lugar de trabajo. Que lo visual no sea solo un estímulo más, sino que resulte en un aporte para lo que quiero enseñar. Que interpele a los alumnos en sus consumos y que, así, les "diga" algo sobre quiénes son o lo que les interesa.

De cuál medio proviene, duración, accesibilidad.

Sí, básicamente la posibilidad de reproducir para los alumnos y el acceso que tendrán a ese material. Si voy a fotocopiar, lo escaneo y lo paso a alto contraste, después lo imprimo. Me aseguro de que la tipografía y los fondos sean aceptables para el alumno.

Como decíamos, no se registraron respuestas que se concentraran específicamente en los contenidos sino en los dos aspectos mencionados. Esto sugiere que una de las grandes preocupaciones de los informantes tiene que ver en primer lugar con la posibilidad efectiva de utilización de los MDV en el marco de sus clases.

\subsection{Funciones asignadas a los materiales visuales}

Indagamos en los modos en que se utilizan los materiales para las clases. La pregunta 11 (¿Con qué propósito utiliza materiales visuales en clase?) nuevamente permitía elegir varias opciones.

Tabla 8.

Propósitos de uso de los materiales visuales.

\begin{tabular}{lll}
\hline Uso didáctico & Cantidad & Porcentaje \\
\hline 1. & Como disparador para la escritura & $63,95 \%$ \\
2. Para establecer comparaciones (entre el contenido disciplinar trabajado y algún & & 59 \\
aspecto del material visual) & 49 & $58,33 \%$ \\
3. Con el fin de situar a los estudiantes en un tema o contexto relevante para trabajar & 73 & $86,90 \%$ \\
$\quad$ contenidos en clase & 32 & $38.09 \%$ \\
4. Para atraer la atención de los estudiantes & 60 & $71,42 \%$ \\
5. Para facilitar/clarificar/reformular algún contenido que considero complejo & 5 & $5,95 \%$ \\
\hline 6. Otros & & \\
\hline
\end{tabular}


Fuente: Elaboración propia.

A partir de los resultados vertidos en la Tabla 8, podemos conceptualizar cuáles son las funciones que los docentes asignan a los materiales visuales en el área de Lengua y Literatura.

Podríamos decir que cada uno de los ejemplos de usos didácticos en la consigna apunta hacia una función y estrategia didáctica diferente. En el siguiente cuadro resumimos las estrategias de uso de los MDV que se desprende de las respuestas:

Tabla 9.

Funciones de los materiales visuales.

\begin{tabular}{|c|c|}
\hline Nombre de la función & Descripción de la función \\
\hline 1. Disparadora & $\begin{array}{l}\text { Motivar la escritura, muchas veces a modo de écfrasis o traducción de la imagen } \\
\text { en algún escrito que toma el MDV como disparador. }\end{array}$ \\
\hline 2. Analógica & $\begin{array}{l}\text { Explicar conceptos generalmente abstractos por medio de comparaciones o } \\
\text { metáforas que lo concretizan }\end{array}$ \\
\hline $\begin{array}{l}\text { 3. Contextualizadora o } \\
\text { referencial }\end{array}$ & Brindar un marco para el abordaje de los contenidos \\
\hline 4. Fático- apelativa & Comprobar la atención y contacto en la situación áulica. \\
\hline 5. Reformuladora & $\begin{array}{l}\text { Para ajustar el código: por ejemplo, el metalenguaje de la materia o conceptos } \\
\text { abordados por medio de alguna reformulación visual }\end{array}$ \\
\hline
\end{tabular}

Fuente: Elaboración propia.

Desde una concepción tradicional que jerarquiza lo visual por debajo de otros sistemas de signos dentro del campo educativo (Dussel, 2009), lo esperable hubiera sido que los informantes privilegiaran la función fático-apelativa para captar la atención de los alumnos por medio de los materiales. Lejos de ello, las respuestas de los docentes revelan estar al tanto de diferentes apropiaciones posibles de los recursos visuales.

De las 32 respuestas que incluyeron esta función, solo 4 la escogieron exclusivamente. Vemos entonces que la identificación unívoca de lo visual con un estímulo sensorial es baja. La mayoría de los docentes opta por usos más elaborados de los materiales visuales. Revisemos algunos testimonios donde se pone el énfasis en alguna de estas funciones.

Entre los usos referidos en la consigna 12 en que predomina la función contextual:

Vemos fragmentos de películas o un capítulo de una serie antes de abordar un tema, por ejemplo

Para trabajar ESI en prácticas del lenguaje utilizo recortes de diarios y revistas en donde se observen distintas problemáticas para discutir.

Trabajamos con fotos de la época de la guerra fría para cronotopo, a veces pinturas

Testimonios donde predomina la función analógica:

Usé películas para ponerlas en diálogo con las obras literarias leídas y ver cómo funcionaban algunos recursos y los rasgos genéricos en ambas. 
Suelo utilizar memes para abordar y poner, respectivamente contenidos del área.

para abordar connotación, detonación les propongo analizar imágenes, también para diferenciar verbos, adjetivos y sustantivos.

Para trabajar los puntos de vista uso esas imágenes en que hay más de una imagen y que depende desde dónde se mire.

Análisis de la relación entre el contenido de una novela y la ilustración de tapa (cotejo de diferentes ilustraciones según editoriales de circulación frecuente).

Como disparador escritural:

Presentar distintas imágenes que se relacionen con un área y que permita la escritura de lo observado.

He llevado imágenes de diosas y dioses griegos para que los/as estudiantes realicen la producción textual de un mito.

Escritura creativa a partir de una imagen.

Para iniciar alguna actividad de escritura, para ver la descripción, etc.

Imagen como disparador para escritura creativa, no para otra cosa.

Presentar distintas imágenes que se relacionen con un área y que permita la escritura de lo observado.

Usos donde se enfatiza la reformulación:

Armo con los alumnos afiches con las definiciones centrales de los contenidos curriculares para que queden presentes en el aula durante el año

Lectura de la Odisea y producción de memes al respecto

Redes conceptuales, cuadros comparativos, medios gráficos.

Si bien lo anterior es una selección, la opción sobre la que más respuestas hubo, aun sin ser la más elegida, fue la función analógica. 


\subsection{Formación de grado en relación con materiales didácticos}

Las consignas confeccionadas para esta última sección indagan en la formación docente de base y posterior. El objetivo es diferenciar las trayectorias formativas de las destrezas y representaciones que los encuestados ponen en juego. Como observamos en el análisis del punto anterior, los encuestados manifiestan conocer, apreciar y utilizar la dimensión visual de los materiales. Sin embargo, cuando revisamos las trayectorias formativas, esos conocimientos y valoraciones parecen tener un vínculo más estrecho con el quehacer cotidiano de su tarea que con una formación específica en torno a dichas herramientas.

En las preguntas de la tercera sección se indagó en la formación de grado: si esta contó con espacios curriculares en donde se reflexionará sobre la especificidad de los MDV (preguntas 19 y 20) o materiales didácticos en general (MDG) (21 y 22). Los resultados cuantitativos se muestran en las Tablas 10 y 11.

Tabla 10.

Formación en MDV.

\begin{tabular}{lcc}
\hline $\begin{array}{l}\text { Formación en materiales } \\
\text { didácticos visuales }\end{array}$ & & \\
(en grado) & Cantidad & Porcentaje \\
\hline No & 60 & $71,42 \%$ \\
Sí & 24 & $28,58 \%$ \\
\hline
\end{tabular}

Fuente: Elaboración propia.

Tabla 11.

Formación en MDG.

\begin{tabular}{lcc}
\hline $\begin{array}{l}\text { Formación en materiales } \\
\text { didácticos en general } \\
\text { (en grado) }\end{array}$ & Cantidad & Porcentaje \\
\hline No & 56 & $66,66 \%$ \\
Sí & 28 & $34,34 \%$ \\
\hline
\end{tabular}

. Fuente: Elaboración propia.

Lo primero que podemos destacar es la baja proporción de casos en que los encuestados identificaron espacios curriculares formativos en torno a los materiales (visuales o no). Se destaca una leve alza en el caso de la formación en MDG. No obstante, es incluso más interesante lo que arrojan las respuestas que analizaremos desde una mirada cualitativa.

Si cruzamos las respuestas de esta sección con las instituciones de formación de base de los informantes - universidades nacionales (UUNN) o institutos (ISDF) ${ }^{4}$ se revela cierta continuidad.

\footnotetext{
${ }^{4}$ En Argentina, el nivel de educación superior para carreras docentes se concentra en dos tipos de instituciones: por un lado, las UUNN y los ISDF, también llamados "institutos terciarios".
} 
Las preguntas 19 y 20 sobre formación en relación con MDV fueron respondidas en forma afirmativa por 24 informantes. De estos, sólo 5 casos de egresados universitarios respondieron haber recibido tal formación. Las materias en que manifiestan haberlo hecho son Didáctica de la Lengua y la Literatura, Práctica Docente y, en un solo caso, Literatura Española. Por el contrario, en el resto de los informantes de ISFD (19 casos) se menciona una mayor variedad de espacios curriculares donde se formaron en MDV, incluso brindando ejemplos de varias materias en una misma respuesta. En el caso de los ISFD los espacios curriculares más señalados fueron (en orden de mayor a menor frecuencia) Semiótica, Lingüística, Historia de la Literatura y Didáctica de la Lengua y la Literatura, así como los diferentes niveles del Espacio de la Práctica Docente entre los profesores de lengua. Si nos remitimos a los pocos casos de informantes de la carrera de Educación Primaria, la mayor frecuencia de formación en la temática y diversidad de espacios también se mantiene: estos informantes agregaron menciones a talleres optativos transversales y Didácticas específicas. Parece, entonces, que en la formación universitaria se trabaja la formación en MDV en menos cantidad y diversidad de espacios que en los ISFD.

En el caso de los MDG persiste la misma tendencia en cuanto a las proporciones y diversidad de espacios curriculares. 9 informantes universitarios volvieron a mencionar solo espacios como las didácticas específicas y prácticas docentes mientras que los de ISFD se repitieron muchas de las opciones que mencionaron en las respuestas anteriores y se agregaron otros como Didáctica General, Taller de Expresión Oral y Escrita, Educación y TIC.

Para interpretar estas tendencias recurrimos a una exploración de fuentes. Revisamos los planes de estudio de los profesorados del territorio bonaerense y de CABA (ISPP Joaquín V González, ISFD bonaerenses, UUNN), ${ }^{5}$ jurisdicciones a las que pertenecía la mayor parte de los informantes que respondieron afirmativamente. Observamos que la carga de materias de reflexión pedagógico-didáctica es mayor en los ISFD al igual que la cantidad de Espacios de la Práctica. Los profesorados de lengua de institutos superiores también poseen materias como Semiótica o talleres interdisciplinarios que no suelen encontrarse en los profesorados universitarios de la región o que poseen solo en uso pocos casos. Existe otra diferencia institucional que puede ayudar a interpretar las respuestas de los encuestados: sabemos que la tradición formativa de los ISFD se aboca a la docencia mientras que en las UUNN los alumnos de Letras/Lengua y Literatura comparten gran parte de la trayectoria formativa con estudiantes de la

\footnotetext{
5 Todos los ISFD bonaerenses poseen el mismo diseño curricular. Al momento del muestreo se encontraba vigente el de 1999 y las primeras implementaciones del nuevo diseño aprobado en 2018. En cambio, las UUNN, debido al principio de autonomía universitaria en el país, poseen cada una sus propias organizaciones curriculares.
} 
licenciatura. En la universidad, entonces, un área como Lengua y Literatura se trabaja desde una carrera abocada a la docencia y otra a la investigación. En los ISFD no hay tal coexistencia con la formación en investigación y la formación se aboca claramente a la formación de futuros profesores. Esto último, sumado a su organización curricular propicia un trabajo más próximo y constante con la reflexión de la práctica docente en las diferentes materias, incluso una reflexión interdisciplinaria e integrada. ${ }^{6}$

\subsection{Formación complementaria}

Revisaremos a continuación las preguntas relacionadas con la formación docente que complementa a la de grado; nos referimos a la denominada "capacitación docente" como así también a la formación en posgrados y postitulación. Este amplio conjunto de ofertas y modalidades formativas incluye cursos, talleres, seminarios, jornadas, capacitaciones en servicio o carreras que no están comprendidas en el grado. ${ }^{7}$

Ante la pregunta 23, la mitad de los informantes respondió no haber participado en espacios de capacitación (Tabla 12) sobre la temática MDV.

Tabla 12

Capacitación

\begin{tabular}{lll}
\hline $\begin{array}{l}\text { Participación en espacios } \\
\text { de capacitación sobre MDV }\end{array}$ & Cantidad & Porcentaje \\
\hline No & 43 & $51,19 \%$ \\
$\begin{array}{l}\text { Sí (sobre materiales } \\
\text { visuales para uso general) }\end{array}$ & 25 & $29,71 \%$ \\
$\begin{array}{l}\text { Sí (sobre materiales } \\
\text { visuales para LyL) }\end{array}$ & 16 & $19,04 \%$ \\
\hline
\end{tabular}

Fuente: Elaboración propia.

La pregunta 24 indagaba en las instituciones donde tuvieron lugar esas experiencias. A partir del análisis de las respuestas encontramos otro hecho llamativo.

\footnotetext{
${ }^{6}$ Cabe destacar que en materia de correlación con el período temporal la mayoría de quienes afirmaron haber contado con una preparación referida a MDG o MDV en su formación de base fueron egresados que finalizaron sus estudios entre 1 y 5 años previos a la encuesta. No parece haber una vinculación entre esa concentración en el último lustro o no con renovaciones de planes de estudio. Los de las UUNN revisados no han cambiado en dicho período en la mayoría de los casos; el de profesorado en terciario del territorio bonaerense cambió en 2018 aunque no hubo grandes movimientos en la estructura curricular con respecto al plan de estudios anterior. ${ }^{7}$ En Argentina la oferta de formación continua o complementaria podría dividir en dos tramos. Por un lado, las carreras de posgrado suelen estar asociada con las UUNN, aunque el INFoD incorporó algunas carreras de complementación y postulación por medio del programa Nuestra Escuela. En segundo, lugar, el circuito de capacitación. En general consiste en cursos, talleres, seminarios o jornadas. Los referentes más habituales dentro de este circuito son el INFoD a nivel nacional (con una amplia oferta de cursos con modalidad predominantemente virtual o semipresencial en todo el territorio nacional). Luego están los Centros de Información, Investigación Educativa (CIIE) cuya jurisdicción también es regional y brindan cursos con diferentes modalidades. Las UUNN en general no ofrecen cursos de capacitación, aunque ocasionalmente en el marco de la Extensión organizan cursos destinados a un público que no se encuentra dentro del circuito de la formación de grado o investigación.
} 
De las 16 respuestas sobre formación en MDV pensados específicamente para Lengua y Literatura (Tabla 12), 10 corresponden a propuestas universitarias (cursos de posgrado o extensión) y los 6 restantes a los Centros de Información e Investigación Educativa (CIIE) regionales. En cambio, las experiencias relacionadas con capacitación MDV para uso en diferentes espacios curriculares se reparten mayoritariamente entre Instituto Nacional de Formación Docente (INFoD), CIIE, capacitación en servicio y UUNN.

La oferta relacionada específicamente con MDV para Lengua y Literatura parece estar concentrada en el ámbito universitario mientras que la formación en materiales didácticos de uso común para diferentes áreas curriculares se presenta en mayor diversidad de instituciones formadoras. Es significativo, sin embargo, que la oferta de INFoD en cuanto a materiales didácticos, según los encuestados, parezca ser generalista, es decir, que no tiene arraigo en un área curricular específica. Esto nos habla de una concepción probablemente más cercana a la didáctica general que a las específicas en los espacios formativos de INFoD. Otra situación llamativa es la segmentación que se observa en la trayectoria de los encuestados y sus experiencias de capacitación. Los informantes que refirieron participar en tales espacios dentro de UUNN fueron todos graduados de carreras universitarias. En cambio, en las ofertas de capacitación a cargo de INFoD, los CIIE y capacitaciones en servicio (por ejemplo, del PNFP) participaron sobre todo docentes que egresaron de institutos terciarios y algunos universitarios. Se presenta entonces una segmentación en el circuito de formación complementaria al grado. La correlación que parece arrojar este sondeo sería la siguiente:

Tabla 13.

Correlación entre egreso y formación complementaria.

\begin{tabular}{lll}
\hline Temática & $\begin{array}{l}\text { Institución que brinda formación } \\
\text { complementaria }\end{array}$ & $\begin{array}{l}\text { Participante del espacio de formación } \\
\text { en cuestión }\end{array}$ \\
\hline $\begin{array}{l}\text { MDV para Lengua y } \\
\text { Literatura }\end{array}$ & UUNN & Egresado universitario \\
MDV para uso general & INFoD, CIIE, otros & Egresados terciarios y universitarios \\
\hline \multicolumn{2}{l}{ Fuente: Elaboración propia. }
\end{tabular}

Desconocemos los factores causales de esta tendencia. Es probable que incida una combinación de factores entre los muchos posibles. A saber: diferencias en la comunicación institucional de las UUNN frente a la de las otras instituciones formativas; la modalidad ofrecida para dichos cursos, situaciones como la distancia geográfica; interés en la temática; familiaridad o afinidad con la institución, etc. Algunos de estos posibles factores son claramente más subjetivos que otros y difíciles de sistematizar, objetivo que excede los de este trabajo. Por otro lado, la escasa mención de la capacitación en servicio (solo 3 casos de todas las 
respuestas afirmativas) ameritaría una indagación futura y sistemática acerca de las temáticas y enfoques cubiertas por los planes y programas estatales para la capacitación en horario y ámbito institucional

\section{Conclusiones}

\section{a) Escasez en la formación de base}

La primera conclusión que podemos delinear es, a grandes rasgos, una falta de formación de base para los docentes en relación con los MDV y MDG. Como vimos con ambos tipos de materiales, más de la mitad de los informantes dijo no haber recibido preparación específica en cada caso (Tablas 10 y 11). Esto no significa necesariamente que la mayoría de los informantes no haya recibido preparación para elaborar propuestas de enseñanza (secuencias, proyectos, unidades, planificaciones, etc.) sino que refieren no haber contado con formación específica para la elaboración y selección de MD. En toda propuesta didáctica, por supuesto, se crean o seleccionan materiales, pero la proporción de las respuestas por la negativa señala al menos una falta de sistematicidad y especificidad en la preparación docente sobre dicho contenido.

\section{b) Diferencia en la trayectoria formativa de base}

Las correlaciones entre las respuestas muestran que las diferencias en la cantidad y diversidad de espacios formativos tienen cierto grado de vinculación con el tipo de institución que brindó la formación de base (UUNN o ISFD). Según los resultados y el análisis de los datos de la Tablas 12 y 13, se produce una segmentación más marcada en la formación complementaria, es decir, en el circuito de capacitaciones y formación continua. La temática de MDV para Lengua y Literatura o para usos generales se muestra diferenciada por el tipo de institución, y aparentemente hay una tendencia también en el acceso a dichas propuestas según el perfil de egreso de los informantes. Sobre este punto se necesitarían estudios con una muestra más amplia para confirmar o relativizar los alcances de nuestras observaciones.

\section{c) Representación asignada a la injerencia de lo visual en la tarea docente}

A pesar de la manifiesta falta de formación de grado en MD en particular, los informantes, en una cantidad apabullante, reconocen la importancia de la visualidad en los procesos de enseñanza-aprendizaje mediados por los recursos. 96,42\% de los encuestados dijo considerar los aspectos visuales al momento de diseñar sus materiales y 97,61 \% cuando los seleccionan. Los informantes manifiestan tal atención ya sea en relación con la legibilidad o el usufructo del recurso por su vínculo con los contenidos, como se analizó en las respuestas posteriores. Esto nos permite inferir que el aspecto visual es reconocido como una dimensión 
importante para la práctica profesional, que los informantes han llegado a advertirlo, a incorporar herramientas por su propia cuenta y gracias a las necesidades derivadas del trabajo docente. En ese sentido, la distancia entre la formación y el ejercicio de la profesión se muestra con mucha claridad. El conocimiento sobre la dimensión visual de los materiales didácticos queda librado a las trayectorias profesionales de cada informante (destrezas e intereses de cada docente, recomendaciones que recibe de colegas) y a la oferta de capacitación de cada jurisdicción.

La indagación en lo que los docentes identifican como materiales visuales muestra también una concepción predominantemente orientada hacia lo icónico. Esto podría apuntar, quizá, hacia la formación de base ya sea por la presencia o la ausencia de espacios curriculares en los que se reflexione sobre estos otros sistemas de signos y sus interacciones con la construcción de los mensajes verbales.

\section{d) Importancia para la formación docente}

En cualquier contexto, el fortalecimiento de la formación de nuevos profesores requiere una preparación para diversidad de situaciones y necesidades. Se trata de un desafío para nada sencillo de acometer por parte de quienes nos encontramos a cargo de espacios formativos. No podemos dejar de señalar que, en una coyuntura como la que hemos atravesado en 2020, esta temática ha adquirido una especial relevancia. En conjunto con la incorporación de las TIC, la elaboración y selección de materiales visuales se mostró como una dimensión ineludible para la tarea educativa.

Por otra parte, los testimonios de los informantes en torno a la injerencia que asignan a la visualidad revelan interés y necesidad de contar con una formación que contribuya a la práctica profesional.

\section{Referencias}

Acaso, María. El lenguaje visual. Madrid: Planeta, 2006.

Alvarado, Maite. Paratexto. Buenos Aires: EUDEBA, 1995.

Área Moreira, M. (2004). Los medios y las tecnologías en la educación. Madrid: Pirámide.

Capasso, Verónica. "Estudios visuales: aportes y notas para pensar el presente". El Ornitorrinco Tachado, 12 (2020).

Ciafardo, Mariel. “¿Cuáles son nuestras sirenas? Aportes para enseñanza del lenguaje visual”. Revista Iberoamericana de Educación, 52.2 (2010): 2-8. 
Cuesta, Carolina y Bombini, Gustavo. "Lengua y literatura: Campo de la didáctica específica y prácticas de la enseñanza”. En: Gemma Fioriti (Comp.). Didácticas específicas: Reflexiones y aportes para la enseñanza. Buenos Aires: Miño y Dávila, 2006.

Cuesta, Carolina. Didáctica de la lengua y la literatura, políticas educativas y trabajo docente. Problemas metodológicos de la enseñanza. Buenos Aires: Miño y Dávila, 2019.

Cuesta, Carolina. Lengua y Literatura: disciplina escolar. Hacia una metodología circunstanciada de su enseñanza. Tesis doctoral publicada en línea. Universidad Nacional de La Plata, Argentina (2012). http://www.memoria.fahce.unlp.edu.ar/tesis/te.641/te.641.pdf

Davini, María Cristina. Métodos de enseñanza.: didáctica general para maestros y profesores. Buenos Aires: Santillana, 2008.

Dussel, Inés. "Escuela y saberes en la cultura digital” [Online videoclip]. YouTube. 4 de diciembre de 2012. <https://www.youtube.com/watch?v=qRmsK7df9Wg>

Dussel, Inés. "Escuela y cultura de la imagen: los nuevos desafíos”. Nómadas. 30 (2009): 180-193.

Gagliardi, Lucas. “Cultura visual, Lengua y Literatura: territorios en común”. Plurentes. Artes y Letras. 11 (2020a). <https://doi.org/10.24215/18536212e002>

Gagliardi, Lucas. "Memes en la clase de lengua y literatura: Qué, para qué y cómo”. Convergencias. 3.5 (2020b): 25-49. <http://www.memoria.fahce.unlp.edu.ar/art_revistas/pr.11612/pr.11612.pdf>

Hernández, Fernando. Educación y cultura visual. Madrid: Octaedro, 2010.

Imperatore, Adriana. "Cambios de concepción y usos acerca de los materiales didácticos para la educación superior en entornos virtuale”. En Pérez, S. e Imperatore, A. (Comps.). Comunicación y educación en entornos virtuales de aprendizaje: Perspectivas teóricometodológicas. Bernal: Universidad Nacional de Quilmes Editorial, 2009.

Kress, Gunther y Van Leeuwen, Theo. Multimodal discourse: The modes and media of contemporary communication. London: Arnold, 2006. 
López Corral, Manuela. "Relatos góticos y creepypasta: La narrativa tradicional oral puesta en relación con los intereses de los jóvenes". En: $3^{\circ}$ Jornadas de TIC e Innovación en el Aula: "Enlaces entre educación, conocimiento libre y tecnologías digitales". La Plata: Universidad Nacional de La Plata (2015).

López Corral, Manuela. Enseñanza de la literatura y fanfiction: Continuidades entre saberes escolares y consumos culturales juveniles. Tesis de grado publicada en línea. Universidad Nacional de La Plata, Argentina (2020). http://www.memoria.fahce.unlp.edu.ar/tesis/te.1828/te.1828.pdf

Ministerio de Educación. Núcleos de aprendizaje prioritarios. Buenos Aires: Ministerio de Educación, 2006.

Mitzoreff, Nicholas. An Introduction to Visual Culture. Nueva York: Roultledge, 1999.

Riestra, Dora y Tapia, Stella Maris. "El momento de la reflexión sobre la lengua en el aula: ¿Explicación gramatical azarosa o sistematización de contenidos específicos?”. Saga. Revista de Letras. 1.1 (2014): 178-206.

Rockwell, Elsie. La experiencia etnográfica. Historia y cultura en los procesos educativos. Buenos Aires: Paidós, 2009.

Schwartzman, Gisela. "Materiales didácticos en educación en línea: por qué, para qué, cómo”. En Brocca, D. I Jornadas Nacionales III Jornadas de la UNC: experiencias e investigación en educación a distancia y tecnología educativa. Universidad Nacional de Córdoba, Córdoba, 2013.

Strauss, Anselm y Corbin, Juliet. Bases de la investigación cualitativa. Técnicas y procedimientos para desarrollar la teoría fundamentada. Bogotá: CONTUS, 2002.

Viñao, Antonio. Sistemas educativos, culturas escolares y reformas: continuidades y cambios. Madrid: Morata, 2002.

\section{Anexos}

\section{Anexo I: Preguntas de la encuesta}

1. ¿En qué territorio nacional reside actualmente?

2. ¿Cuál es su carrera de formación de grado?

Lengua y Literatura

Educación Primaria

Otra 
3. En caso de haber respondido "otra", indicar titulación

4. ¿Dónde realizó su formación profesional como docente?

Universidad

Terciario

5. ¿Cuándo egresó de su carrera de formación docente?

Entre 1 y 5 años

Entre 5 y 10 años

Entre 10 y 15 años

Más de 15 años

6. ¿Se desempeña como docente en la actualidad?

Sí

No

7. En caso de haber respondido en forma afirmativa, ¿en qué nivel del sistema educativo se desempeña dando clases en espacios curriculares del área?

Primaria

Secundaria

8. ¿Cuánto tiempo lleva en el desempeño de la docencia?

Entre 1 y 5 años

Entre 5 y 10 años

Entre 10 y 15 años

Más de 15 años

9. ¿Cuáles de los siguientes ejemplos considera como "materiales visuales"? (puede elegir más de una opción) [se incluyen los ejemplos en la Imagen 1]

10. En relación con la pregunta anterior, puede comentar brevemente por qué alguno de los ejemplos 1 a 6 no representa un material visual

11. ¿Con qué propósito utiliza materiales visuales en clase? (Elija un máximo de dos opciones pensando en los usos más frecuentes dentro de su práctica profesional)

Como disparador para la escritura.

Para establecer comparaciones (entre el contenido disciplinar trabajado y algún aspecto del material visual). Con el fin de situar a los estudiantes en un tema o contexto relevante para trabajar contenidos en clase.

Para atraer la atención de los estudiantes 
Para facilitar/clarificar/reformular algún contenido que considero complejo

Otros

12. ¿Puede indicar alguna actividad concreta en la cual se observe alguno de los usos que seleccionó en el punto anterior? (No es necesario que detalle su implementación en forma pormenorizada sino identificar la actividad a partir de la diferencia que presente con las del punto anterior)

13. Cuando usted selecciona materiales ¿tiene en cuenta aspectos visuales?

Sí

No

14. En caso de haber respondido de modo afirmativo ¿cuáles aspectos visuales toma en cuenta para seleccionar materiales?

15. Cuando usted prepara sus propios materiales (consignas, cuadernillos, imágenes, etc.) ¿tiene en cuenta aspectos visuales?

Sí

No

16. En caso de haber respondido de modo afirmativo ¿cuáles aspectos visuales tiene en cuenta para diseñar sus propios materiales?

17. Cuando da actividades a sus estudiantes ¿contempla que ellos usen recursos visuales para resolverlas?

Siempre

En ocasiones

Nunca

18. En caso de haber respondido afirmativamente: ¿qué aspectos contempla?

19. En su formación de grado ¿trabajó en algún espacio curricular la especificidad de los materiales visuales para la enseñanza de contenidos de Lengua y Literatura?

Sí

No

20. En caso de haber respondido afirmativamente, especifique en nombre del/los espacio/s curricular/es en que trabajó la especificidad de los materiales visuales para Lengua y Literatura

21. En su formación de grado ¿trabajó en algún espacio curricular el armado de materiales didácticos en general para la enseñanza de Lengua y Literatura?

Sí 
No

22. En caso de haber respondido afirmativamente, especifique en nombre del/los espacio/s curricular/es en que trabajó con dicha temática

23. ¿Realizó capacitaciones docentes sobre la temática del uso de materiales visuales en el aula?

Sí (específicamente sobre materiales visuales para Lengua y Literatura)

Sí (sobre materiales visuales, pero no de uso específico para el área curricular)

No

24. En caso de haber respondido afirmativamente: ¿dónde realizó dicha capacitación?

En una universidad (posgrado, extensión, etc.).

En un instituto de formación docente

En un Centro de Capacitación, Información e Investigación Educativa (CIIE)

En la escuela, por medio de un programa de capacitación (PFNP, etc.) en horario de servicio.

En cursos de capacitación del INFoD

25. Dicha capacitación tuvo modalidad

Virtual

Semipresencial

Presencial

\section{Anexo II: Índice de siglas}

CABA: Ciudad Autónoma de Buenos Aires

CIIE: Centro de Información e Investigación Educativa

INFoD: Instituto Nacional de Formación Docente

ISFD: Instituto Superior de Formación docente

MDG: Material didáctico en general

MDV: Material didáctico visual

UUNN: Universidades nacionales 